\title{
Characterizing sustainability in discrete time
}

\author{
Geir B. Asheim ${ }^{1}$ (D) Tapan Mitra ${ }^{2}$
}

Received: 2 February 2019 / Accepted: 30 January 2020 / Published online: 13 February 2020

(c) The Author(s) 2020

\begin{abstract}
We examine the investment rule that must be satisfied by an efficient and egalitarian path in a discrete-time version of the Dasgupta-Heal-Solow model of capital accumulation and resource depletion. In the discrete-time model, competitive valuation of net investments in terms of early and late pricing differs. We redefine Hartwick's rule to require zero value of net investments at a valuation rule intermediate between these two. Using this definition, we show that along an efficient and egalitarian path, Hartwick's rule is followed in all time periods. We thereby establish the converse of Hartwick's result in discrete time, and we do so under weaker assumptions than those in the existing literature on how output varies as a function of capital and resource use. Our redefinition of Hartwick's rule follows naturally if discrete time is viewed as providing information at discrete points in time of an underlying continuous-time process.
\end{abstract}

Keywords Intergenerational equity $\cdot$ Sustainable development $\cdot$ Hartwick's rule

JEL Classification D63 · O41 - Q01

\section{Introduction}

Hartwick's rule for sustainability prescribes reinvesting resource rents, thus keeping the value of net investments equal to zero. Originating from Hartwick's original article (Hartwick 1977), a series of papers (among others, Dixit et al. 1980; Withagen and Asheim 1998; Mitra 2002; Asheim et al. 2003; Buchholz et al. 2005; Mitra et al.

Tapan Mitra passed away on 3 February 2019, just after the initial submission of this paper. Tapan Mitra was an excellent scholar and great human being with whom is was a privilege to cooperate. Asheim has sought to revise the paper consistent with high standards that he sat for his work.

Geir B. Asheim

g.b.asheim@econ.uio.no

1 Department of Economics, University of Oslo, P.O. Box 1095, Blindern, 0317 Oslo, Norway

2 Department of Economics, Cornell University, 448 Uris Hall, Ithaca, NY 14853, USA 
2013) have contributed to our understanding of the connection between Hartwick's rule and a sustainable development with constant well-being.

These contributions show how Hartwick's rule for sustainability corresponds to paths which keep well-being constant (are egalitarian) and where well-being cannot be increased for some subinterval of time without being decreased at some other subinterval (are efficient). This correspondence can be stated through the following two results:

Hartwick's result If along an efficient path Hartwick's rule is followed forever, then an egalitarian path is implemented.

The converse of Hartwick's result If an efficient and egalitarian path is implemented, then Hartwick's rule is followed forever.

Asheim (2013) presents an overview of how these results obtain in three different classes of technologies: (1) the one-sector growth model, (2) the model of capital accumulation and resource depletion used by Hartwick, and (3) a general model with multiple capital goods.

Now, these results are established under assumptions that are rather strict: The economy is assumed to have constant technology and constant population. Furthermore, the economy is assumed to implement an efficient path in continuous time. There are ways to relax each of these assumptions and still obtain some variant of Hartwick's result and its converse. For example, if there is exogenous technological progress in the sense of a time-dependent technology, we may restore these results by including time as an additional stock.

In this paper, we focus on how to relax the assumption that time is continuous. In reality, accounting for the value of net investments will take place at discrete points in time. Furthermore, Fleurbaey (2015, p. 35) suggests that the concept of sustainable development be analyzed in discrete time "because discrete time makes it possible to obtain a clear distinction between what the current period does and what the next periods can do given the capital stocks they inherit". Thus, it is of interest to investigate to what extent the relationship between Hartwick's rule and a sustainable development with constant well-being survives in a discrete-time setting. This question was already raised by Dasgupta and Mitra (1983) in a discrete-time version of the model of capital accumulation and resource depletion used by Hartwick. The results were discouraging in the sense that Hartwick's rule is not exactly followed along an efficient and egalitarian path, even if technology and population are constant and rather strong assumptions are imposed on the production function.

This paper shows how the converse of Hartwick's result obtains in the model of capital accumulation and resource depletion under weaker assumptions than those imposed by Dasgupta and Mitra (1983). In particular, we impose only regular neoclassical assumption on how net production is a function of the capital and resource use, while relaxing a requirement that resource use has a non-vanishing functional share of output as resource use approaches zero. And even though the competitive prices along such an efficient and egalitarian path do not provide the precise price ratio for which the value of net investments is zero, we show that such prices at the discrete points in time yield a narrow interval for the price ratio 
that gives zero value of net investments when going from one point in time to the next.

The proof of this result is based on the following observation made by Malinvaud (1953) in discrete time and developed in the context of efficient and egalitarian paths in continuous time by Mitra (2002): Vectors of initial stocks that are sufficient to maintain well-being at or above a given level $c$ form a convex set $S(c)$. Furthermore, there is a relative price between capital and resource at which the vector of initial stocks that leads to an efficient and egalitarian path with wellbeing kept constant at $c$ minimizes the cost of stocks evaluated over all vectors in $S(c)$. Finally, by applying a suggestion made by Dasgupta and Mitra (1983, Section 7), we show that this relative price is exactly the ratio of gross capital productivity to productivity of resource use, which is the competitive price ratio that compares the value of stock changes in the context of Hartwick's rule. Note that this last step is non-trivial and essential, as Hartwick's rule is defined in terms of competitive prices, not in terms of the "maximin" prices that support the set $S(c)$ and which can be derived from the partial derivatives of the maximin value function.

The fact that the competitive value of stock is minimized is sufficient to establish that the competitive valuation of net investments between time period $t$ and time period $t+1$ is nonnegative when valued at the (higher) early price ratio at $t$ and nonpositive when valued at the (lower) late price ratio at $t+1$. Hence, there exists an intermediate price ratio of capital augmentation to resource use, between the one at $t+1$ and the one at $t$, that leads to zero value of net investments. Thus, by redefining Hartwick's rule to require zero value of net investments at some valuation rule intermediate between early and late pricing, we show that Hartwick's rule is followed in all time periods along an efficient and egalitarian path.

Compared to Dasgupta and Mitra (1983), we make the timing of prices more transparent, allowing us to introduce the terms "early" and "late" pricing and setting the stage for redefining Hartwick's rule in a manner appropriate for discrete time.

Moreover, by weakening the assumptions on the production function, we establish a significantly stronger result. With their additional assumption, namely that resource use has a non-vanishing functional share of output as resource use approaches zero, Dasgupta and Mitra (1983, Theorem 1) show that if it is feasible to keep consumption bounded away from zero starting with given initial stocks of capital and resource, then these stocks can also give rise to an efficient and egalitarian path. Hence, this assumption means that the maximin problem of maximizing the infimum of consumption leads to an efficient and egalitarian path whenever the infimum is positive. Note that such a result cannot be established in the one-sector model of capital accumulation if there is a finite Golden Rule capital stock, since there exists no efficient and egalitarian solution to the maximin problem for initial stocks exceeding the Golden Rule size. Mitra et al. (2013, Theorem 2) indicate that the present model, which includes resource depletion, has similar properties: If initial stocks of capital and resource are too large, there might not exist any efficient and egalitarian path, even though these stocks are sufficient to keep consumption bounded away from zero. While the analysis of Dasgupta and Mitra (1983) is not applicable under such circumstances, we show that the converse of Hartwick's result 
holds for any initial stocks that leads to an efficient and egalitarian solution to the maximin problem; this corresponds to the analogous result in the one-sector model.

We start out in Sect. 2 by presenting the assumptions that we impose on the model of capital accumulation and resource depletion. We define properties for paths in this model, derive preliminary results on the competitive price support of interior paths (with positive capital and resource use in each time period), and adapt the definition of Hartwick's rule to the discrete-time setting. We then proceed in Sect. 3 to prove that the converse of Hartwick's result holds even in discrete time, as well as suggesting how this result can be generalized beyond the model of capital accumulation and resource depletion.

In the concluding Sect. 4, we show how our redefinition of Hartwick's rule follows naturally if we view discrete time as providing information at discrete points in time of an underlying continuous-time process. This perspective allows us to relate our adaptation of Hartwick's rule to discrete time to the continuous-time version of the converse of Hartwick's result. Furthermore, we discuss the challenges faced when attempting to establish Hartwick's rule as a prescriptive rule in a discrete-time setting. In particular, we pose the question whether Hartwick's result can be demonstrated in discrete time, so that a policy of zero value of net investments can be used to steer the economy along an efficient and egalitarian path. All proofs-except the demonstration of our main result — are contained in the "Appendix".

\section{Framework}

Consider a model with one produced good, which serves as both the capital and the consumption good, and an exhaustible resource. Labor is assumed to be constant over time. The framework described below is the standard one employed in the literature on intertemporal resource allocation in the presence of an exhaustible resource (see, for example, Solow 1974; Dasgupta and Heal 1974), modified by a discretetime formulation of the economic dynamics, following Mitra (1978) and Dasgupta and Mitra (1983). We refer to this as the discrete-time DHS model.

Denote by $k$ the stock of the augmentable capital good (which is assumed to be non-depreciating), and by $r$ the flow of exhaustible resource use. Let $G: \mathbb{R}_{+}^{2} \rightarrow \mathbb{R}_{+}$ denote the production function for the capital/consumption good; the production process uses the capital stock, $k$, and the exhaustible resource use, $r$, as inputs. The net output $G(k, r)$ is used to provide consumption $c$-being an indicator of wellbeing-or to provide augmentation of $k$. Output $G(k, r)$ is the only source of flow of consumption or of net investment.

We will use the following standard assumptions on the production function $G$.

(G1) $G(k, r)$ is a function from $\mathbb{R}_{+}^{2}$ to $\mathbb{R}_{+}$, which is continuous, non-decreasing, and concave in $(k, r)$ on $\mathbb{R}_{+}^{2}$.

(G2) $G(k, 0)=G(0, r)=0$ for all $(k, r) \in \mathbb{R}_{+}^{2}$.

(G3) $G$ is strictly increasing in each argument on $\mathbb{R}_{++}^{2}$, and continuously differentiable in $(k, r)$ on $\mathbb{R}_{++}^{2}$, with $G_{k}(k, r)>0$ and $G_{r}(k, r)>0$ for all $(k, r) \in \mathbb{R}_{++}^{2}$. 
These assumptions impose regular neoclassical properties and correspond to assumptions (A1)-(A3) of Dasgupta and Mitra (1983). However, our results do not require assumption (A4) (or (A4')) of Dasgupta and Mitra (1983), imposing that resource use is "important" in the sense that resource use has a non-vanishing functional share of output as resource use approaches zero. Assumptions (G1)-(G3) (as well as assumptions (A4) and (A4') of Dasgupta and Mitra 1983) are always satisfied when $G$ takes the Cobb-Douglas form (used by Solow 1974):

$$
G(k, r)=k^{\alpha} r^{\beta} \quad \text { for all }(k, r) \in \mathbb{R}_{+}^{2},
$$

with $\alpha>0, \beta>0, \alpha+\beta<1$. Simple analytical forms satisfying assumptions (G1)-(G3) but not (A4) or (A4') do not seem to be available.

Denote by $m$ the stock of the resource. The transformation of the stocks $k$ and $m$ from time period $t(\geq 0)$ to the next time period $t+1$ satisfies:

$$
\begin{aligned}
& y_{t} \leq G\left(k_{t}, r_{t}\right)+k_{t}, \\
& k_{t+1}=y_{t}-c_{t}, \\
& m_{t+1}=m_{t}-r_{t},
\end{aligned}
$$

where $y_{t}, k_{t}, m_{t}, c_{t}$, and $r_{t}$ are constrained to be nonnegative for all $t \geq 0$. This dynamic transformation can be expressed through the following transformation set:

$$
\mathcal{T}=\left\{\left((k, m),\left(y, m^{\prime}\right)\right): 0 \leq y \leq G\left(k, m-m^{\prime}\right)+k, k \geq 0, m \geq m^{\prime} \geq 0\right\} .
$$

A sequence $\left\{k_{t}, m_{t}, c_{t}\right\}$ is a path from $(k, m) \in \mathbb{R}_{+}^{2}$ if $\left(k_{0}, m_{0}\right)=(k, m)$ and

$$
\left(\left(k_{t}, m_{t}\right),\left(c_{t}+k_{t+1}, m_{t+1}\right)\right) \in \mathcal{T} \quad \text { and } \quad c_{t} \geq 0 \quad \text { for all } t \geq 0 .
$$

Denote by $\mathcal{F}(k, m)$ the set of paths from any $(k, m) \in \mathbb{R}_{+}^{2}$.

We provide a list of properties for paths: A path $\left\{k_{t}, m_{t}, c_{t}\right\}$ from $(k, m) \in \mathbb{R}_{+}^{2}$

- is efficient if there does not exist $\left\{k_{t}^{\prime}, m_{t}^{\prime}, c_{t}^{\prime}\right\} \in \mathcal{F}(k, m)$ with $c_{t}^{\prime} \geq c_{t}$ for all $t \geq 0$ and $c_{s}^{\prime}>c_{s}$ for some $s \geq 0$,

- is egalitarian if $c_{t+1}=c_{t}$ for all $t \geq 0$,

- is interior if $k_{t}>0$ and $m_{t+1}<m_{t}$ for all $t \geq 0$,

- is non-wasteful if $y_{t}=G\left(k_{t}, m_{t}-m_{t+1}\right)+k_{t}$ for all $t \geq 0$,

- is competitive if there is a non-null sequence $\left\{p_{t}, q_{t}\right\}$ of nonnegative price pairs such that, for all $t \geq 0$, we have:

$$
\begin{aligned}
p_{t+1} y_{t}+q_{t+1} m_{t+1}-p_{t} k_{t}-q_{t} m_{t} \geq p_{t+1} y+q_{t+1} m^{\prime}-p_{t} k-q_{t} m & \\
& \quad \text { for all }\left((k, m),\left(y, m^{\prime}\right)\right) \in \mathcal{T}
\end{aligned}
$$

- satisfies Hotelling's rule if $\left\{k_{t}, m_{t}, c_{t}\right\}$ is interior and:

$$
\frac{G_{r}\left(k_{t+1}, m_{t+1}-m_{t+2}\right)}{G_{r}\left(k_{t}, m_{t}-m_{t+1}\right)}=G_{k}\left(k_{t+1}, m_{t+1}-m_{t+2}\right)+1 \quad \text { for all } t \geq 0,
$$

- satisfies the capital-value transversality condition if $\left\{k_{t}, m_{t}, c_{t}\right\}$ is interior and: 


$$
\lim _{t \rightarrow \infty}\left(\frac{G_{k}\left(k_{t}, m_{t}-m_{t+1}\right)+1}{G_{r}\left(k_{t}, m_{t}-m_{t+1}\right)}\right) k_{t}=0,
$$

- satisfies resource exhaustion if:

$$
\lim _{t \rightarrow \infty} m_{t}=0 .
$$

Consider an interior path $\left\{k_{t}, m_{t}, c_{t}\right\}$ from $(k, m) \in \mathbb{R}_{++}^{2}$ and define a sequence $\left\{p_{t}, q_{t}\right\}$ of positive price pairs as follows, where the resource is numéraire:

$$
p_{t}=\frac{G_{k}\left(k_{t}, m_{t}-m_{t+1}\right)+1}{G_{r}\left(k_{t}, m_{t}-m_{t+1}\right)} \quad \text { and } \quad q_{t}=1 \quad \text { for all } t \geq 0 \text {. }
$$

The following result summarizes the principal connections between competitive paths and Hotelling's rule in the context of the discrete-time DHS model.

Lemma 1 Assume (G1)-(G3), and let $\left\{k_{t}, m_{t}, c_{t}\right\}$ be an interior path from $(k, m) \in \mathbb{R}_{++}^{2}$. Then:

(a) If $\left\{k_{t}, m_{t}, c_{t}\right\}$ is non-wasteful and satisfies Hotelling's rule, then $\left\{k_{t}, m_{t}, c_{t}\right\}$ is competitive with associated sequence $\left\{p_{t}, q_{t}\right\}$ of price pairs given by $(\mathrm{P})$.

(b) If $\left\{k_{t}, m_{t}, c_{t}\right\}$ is competitive, then $\left\{p_{t}, q_{t}\right\}$ given by $(\mathrm{P})$ is an associated sequence of price pairs, which is unique up to a positive linear transformation. Furthermore, $\left\{k_{t}, m_{t}, c_{t}\right\}$ is non-wasteful and satisfies Hotelling's rule.

The following corollary is immediate.

Corollary 1 Under $(G 1)-(G 3)$, if $\left\{k_{t}, m_{t}, c_{t}\right\}$ is an interior and competitive path from $(k, m) \in \mathbb{R}_{++}^{2}$ with associated sequence $\left\{p_{t}, q_{t}\right\}$ of price pairs given by $(\mathrm{P})$, then the price sequence $\left\{p_{t}\right\}$ is decreasing.

That the sequence $\left\{p_{t}\right\}$ of capital prices is decreasing corresponds to a positive rate of interest associated with the positive net capital productivity of $G$. It means that the sequence $\left\{p_{t}, q_{t}\right\}$ of positive price pairs as determined by $(\mathrm{P})$ is expressed as present-value prices, where time discounting is an integral part of the price system.

In discrete time, the value of net investments at time $t \geq 0$ along a competitive path, $\left\{k_{t}, m_{t}, c_{t}\right\}$, can be defined in terms of early or late pricing, respectively:

$$
\begin{aligned}
& E_{t}=p_{t}\left(k_{t+1}-k_{t}\right)+\left(m_{t+1}-m_{t}\right), \\
& L_{t}=p_{t+1}\left(k_{t+1}-k_{t}\right)+\left(m_{t+1}-m_{t}\right) .
\end{aligned}
$$

As we will see, these measures of the value of net investments differ along an efficient and egalitarian path and cannot both be zero. Still, we will be able to show that an efficient and egalitarian path is characterized by the requirement that resource rents be reinvested in augmentable capital in all time periods, provided that we adopt some valuation rule intermediate between early and late pricing, as stated in the following adaptation of Hartwick's rule to the discrete-time setting. 
Definition 1 (Hartwick's rule in the discrete-time DHS model) Hartwick's rule is followed in time period $t$ along an interior and competitive path $\left\{k_{t}, m_{t}, c_{t}\right\}$ from $(k, m) \in \mathbb{R}_{++}^{2}$ with associated sequence $\left\{p_{t}, q_{t}\right\}$ of price pairs given by $(\mathrm{P})$ if there exists $p \in\left[p_{t+1}, p_{t}\right]$ such that $p\left(k_{t+1}-k_{t}\right)+\left(m_{t+1}-m_{t}\right)=0$.

\section{Properties of an efficient and egalitarian path}

In this section, we present the main result of the paper (Theorem 1) on efficient and egalitarian paths. As prerequisites of that result, we develop basic properties associated with such paths. These can be conveniently separated into competitive conditions (presented in Sect. 3.1), and conditions on the value of investments (presented in Sect. 3.2).

The converse of Hartwick's result establishes that the Hartwick's rule is followed forever along any efficient and egalitarian path. In order to ensure that this problem is non-trivial, we assume that:

(E) The set $\Omega$ is non-empty,

where $\Omega$ is defined as follows:

$$
\begin{array}{r}
\Omega=\left\{(k, m) \in \mathbb{R}_{++}^{2}:\right. \\
\text { there exists an efficient path }\left\{k_{t}, m_{t}, c_{t}\right\} \text { from }(k, m) \\
\text { such that } \left.c_{t} \text { is a positive constant for all } t \geq 0\right\} .
\end{array}
$$

Condition (E) assumes the existence of a stock pair $(k, m)$ for which the maximin problem of maximizing the infimum of consumption has an efficient and egalitarian solution with positive (constant) consumption. It is analogous to the condition, in the one-sector model of capital accumulation with a concave and continuously differentiable production function, that gross capital productivity exceeds the rate of depreciation as the capital stock approaches zero.

It is, however, demanding to obtain technological conditions that characterize condition (E) in the setting of the discrete-time DHS model. Mitra et al. (2013, Theorems 1 and 2) establish such sufficient and necessary conditions in the continuoustime DHS model. In the discrete-time DHS model, Cass and Mitra (1991) establish sufficient and necessary conditions for the feasibility of keeping consumption bounded away from zero, while Dasgupta and Mitra (1983), by imposing their additional assumption (A4), show that this implies the existence of an efficient and egalitarian path. However, as noted in Introduction, the imposition of assumption (A4) would seriously weaken our main result, by significantly constraining the class of technologies we would consider. Hence, we limit our discussion of technological conditions by noting that, with a Cobb-Douglas production function, as given by (1), every pair $(k, m) \in \mathbb{R}_{++}^{2}$ belongs to $\Omega$ provided $\alpha>\beta$; this can be inferred from results reported in Dasgupta and Mitra (1983) and Cass and Mitra (1991).

Let $(k, m) \in \Omega$. Note that, for any efficient path $\left\{k_{t}, m_{t}, c_{t}\right\}$ from $(k, m)$, such that $c_{t}$ is a positive constant for all $t \geq 0$, we must have the positive constant to be unique. (For if there were two such constants, then the path with the lower constant 
consumption would be inefficient.) Consequently, with each $(k, m) \in \Omega$, we can associate this unique constant consumption level; this is the maximin value, which we write $c(k, m)$. Thus, a consequence of $(\mathrm{E})$ is the following observation:

(E') There are $(k, m) \in \Omega$ and an efficient and egalitarian path $\left\{k_{t}, m_{t}, c_{t}\right\}$ from $(k, m)$ with $c_{t}=c(k, m)>0$ for all $t \geq 0$.

In what follows, we fix a stock pair $(k, m) \in \Omega$ (which exists by condition $(\mathrm{E})$ ), and we fix an efficient and egalitarian path (which exists by observation $\left(E^{\prime}\right)$ ), and denote it by $\left\{k_{t}, m_{t}, c_{t}\right\}$; furthermore, we denote $c(k, m)$ by $c$.

\subsection{Competitive conditions}

We define:

$$
S(c)=\left\{\left(k^{\prime}, m^{\prime}\right) \in \mathbb{R}_{+}^{2}: \text { there exists }\left\{k_{t}^{\prime}, m_{t}^{\prime}, c_{t}^{\prime}\right\} \in \mathcal{F}\left(k^{\prime}, m^{\prime}\right) \text { with } c_{t}^{\prime} \geq c \text { for all } t \geq 0\right\} .
$$

Thus, $S(c)$ is the pair of initial stocks that enable consumption to be maintained at or above $c=c(k, m)>0 .{ }^{1}$ Clearly, for each $t \geq 0$, we have $\left(k_{t}, m_{t}\right) \in S(c)$.

We will note two important properties of the set $S(c)$; these are stated in Lemmas 2 and 3. These properties will be used to establish a "cost minimization" property of an efficient and egalitarian path in Proposition 1.

For statement of the first of these lemmas (as well as for the proof of Proposition 1), define, for each $t \geq 0$, the set of stock vectors where neither stock exceeds $\left(k_{t}, m_{t}\right)$ :

$$
R_{t}=\left\{\left(k^{\prime}, m^{\prime}\right) \in \mathbb{R}_{+}^{2}:\left(k^{\prime}, m^{\prime}\right) \leq\left(k_{t}, m_{t}\right)\right\}
$$

Lemma 2 Under $(G 1)-(G 3)$ and $(E)$, for each $t \geq 0, S(c) \cap R_{t}=\left\{\left(k_{t}, m_{t}\right)\right\}$.

Lemma 2 leads to the following corollary. This has already been established by Dasgupta and Mitra (1983, Proposition 2), but we state and prove the result here for completeness.

Corollary 2 Under $(G 1)-(G 3)$ and $(E)$, the efficient and egalitarian path $\left\{k_{t}, m_{t}, c_{t}\right\}$ from $(k, m) \in \Omega$ with $c_{t}=c>0$ for all $t \geq 0$ is interior and satisfies $k_{t+1}>k_{t}$ for all $t \geq 0$.

Lemma 3 Under $(G 1), S(c)$ is a convex subset of $\mathbb{R}_{+}^{2}$.

\footnotetext{
${ }^{1}$ In the viability approach (Aubin 1991), the set $S(c)$ is referred to as the viability kernel, a concept which is applied in the continuous-time DHS model by Martinet and Doyen (2007) and Doyen and Martinet (2012) and in discrete time by Doyen and Gajardo (2019). Furthermore, the price pair $\left(P_{t}, Q_{t}\right)$ established in Proposition 1 corresponds to an element in the normal cone to the viability kernel $S(c)$ at $\left(k_{t}, m_{t}\right)$.
} 
Proposition 1 Under $(G 1)-(G 3)$ and $(E)$, for each $t \geq 0$, there exists a non-null and nonnegative price pair $\left(P_{t}, Q_{t}\right)$ such that $\left(k_{t}, m_{t}\right)$ minimizes $P_{t} k^{\prime}+Q_{t} m^{\prime}$ over all $\left(k^{\prime}, m^{\prime}\right) \in S(c)$.

The following result shows that the efficient and egalitarian path $\left\{k_{t}, m_{t}, c_{t}\right\}$ from $(k, m) \in \Omega$ with $c_{t}=c>0$ for all $t \geq 0$ satisfies Hotelling's rule, among other properties. Note that the proof of this result only uses the efficiency and interiority of the path; the fact that $\left\{k_{t}, m_{t}, c_{t}\right\}$ is egalitarian is not directly invoked.

Proposition 2 Under (G1)-(G3) and (E), the efficient and egalitarian path $\left\{k_{t}, m_{t}, c_{t}\right\}$ from $(k, m) \in \Omega$ with $c_{t}=c>0$ for all $t \geq 0$ is non-wasteful and satisfies Hotelling's rule and resource exhaustion.

Hence, as an immediate consequence of Proposition 2 and Lemma 1 we can state the following corollary.

Corollary 3 Under $(G 1)-(G 3)$ and $(E)$, the efficient and egalitarian path $\left\{k_{t}, m_{t}, c_{t}\right\}$ from $(k, m) \in \Omega$ with $c_{t}=c>0$ for all $t \geq 0$ is competitive with associated sequence $\left\{p_{t}, q_{t}\right\}$ of price pairs given by $(\mathrm{P})$.

We can now state an important property of an efficient and egalitarian path, namely that it satisfies the "cost minimization" property in terms of competitive prices. In the proof of this result, we utilize the observation that, for each $t \geq 0, S_{t}(c) \subseteq S(c)$, where $S_{t}(c)$ denotes the set of initial pairs of stocks that enable consumption to be maintained at or above $c$, provided that $\left\{k_{\tau}^{\prime}, m_{\tau}^{\prime}, c_{\tau}^{\prime}\right\}$ with $\left(k_{\tau}^{\prime}, m_{\tau}^{\prime}, c_{\tau}^{\prime}\right)=\left(k_{t+1+\tau}, m_{t+1+\tau}, c_{t+1+\tau}\right)$ for all $\tau \geq 0$ is followed from $\left(k_{t+1}, m_{t+1}\right)$ :

$$
S_{t}(c)=\left\{\left(k^{\prime}, m^{\prime}\right):\left(\left(k^{\prime}, m^{\prime}\right),\left(c+k_{t+1}, m_{t+1}\right)\right) \in \mathcal{T}\right\} .
$$

Hence, by Proposition 1 and the fact that $\left(k_{t}, m_{t}\right) \in S_{t}(c)$, we have that, for each $t \geq 0,\left(k_{t}, m_{t}\right)$ minimizes $P_{t} k^{\prime}+Q_{t} m^{\prime}$ over all $\left(k^{\prime}, m^{\prime}\right) \in S_{t}(c)$, which, by the differentiability of $G$, leads to the result that the price ratio $P_{t} / Q_{t}$ equals the competitive price ratio $p_{t}$ as given by $(\mathrm{P})$.

Proposition 3 Assume $(G 1)-(G 3)$ and $(E)$, and let the price sequence $\left\{p_{t}\right\}$ be determined by $(P)$ from the efficient and egalitarian path $\left\{k_{t}, m_{t}, c_{t}\right\}$ from $(k, m) \in \Omega$ with $c_{t}=c>0$ for all $t \geq 0$. Then, for each $t \geq 0$, we have that $\left(k_{t}, m_{t}\right)$ minimizes $p_{t} k^{\prime}+m^{\prime}$ over all $\left(k^{\prime}, m^{\prime}\right) \in S(c)$.

\subsection{Conditions on the value of net investments}

We are now in a position to state the main result of the paper.

Theorem 1 Under (G1)-(G3), if the path $\left\{k_{t}, m_{t}, c_{t}\right\}$ from $(k, m) \in \Omega$ with $c_{t}=c>0$ for all $t \geq 0$ is efficient and egalitarian, then Hartwick's rule as redefined 
in Definition 1 is satisfied in all time periods $t \geq 0$. Furthermore, for all $t \geq 0$, the value of net investments, $E_{t}$, measured in early pricing is nonnegative and nonincreasing, and the value of net investments, $L_{t}$, measured in late pricing is non-positive and non-decreasing. The two measures differ for all $t \geq 0$, but both converge to 0 as $t \rightarrow \infty$.

Proof Assume that the path $\left\{k_{t}, r_{t}, c_{t}\right\}$ from $(k, m) \in \mathbb{R}_{++}^{2}$ is efficient and egalitarian. Hence, by Corollary 3 , the path is competitive with associated sequence $\left\{p_{t}, q_{t}\right\}$ of price pairs given by (P). Furthermore, by Proposition 3, for all $t \geq 0$, $p_{t+1} k_{t+1}+m_{t+1} \leq p_{t+1} k_{t}+m_{t}$, or equivalently:

$$
L_{t}=p_{t+1}\left(k_{t+1}-k_{t}\right)+\left(m_{t+1}-m_{t}\right) \leq 0,
$$

since $\left(k_{t}, m_{t}\right) \in S(c)$ for all $t \geq 0$. Likewise, for all $t \geq 0, p_{t} k_{t}+m_{t} \leq p_{t} k_{t+1}+m_{t+1}$, or equivalently:

$$
E_{t}=p_{t}\left(k_{t+1}-k_{t}\right)+\left(m_{t+1}-m_{t}\right) \geq 0 .
$$

Hence, by (3) and (4), for all $t \geq 0$, there exists $p \in\left[p_{t+1}, p_{t}\right]$ such that

$$
p\left(k_{t+1}-k_{t}\right)+\left(m_{t+1}-m_{t}\right)=0,
$$

since, by Corollaries 1 and 2, the price sequence $\left\{p_{t}\right\}$ is decreasing and the capital sequence $\left\{k_{t}\right\}$ is increasing. This shows that Hartwick's rule as redefined in Definition 1 is satisfied in all time periods $t \geq 0$ along an efficient and egalitarian path.

Since the path $\left\{k_{t}, m_{t}, c_{t}\right\}$ is competitive, it follows from (C) that, for all $t \geq 1$ :

$$
\begin{aligned}
& p_{t+1}\left(c_{t}+k_{t+1}\right)+m_{t+1}-p_{t} k_{t}-m_{t} \geq p_{t+1}\left(c_{t-1}+k_{t}\right)+m_{t}-p_{t} k_{t-1}-m_{t-1}, \\
& p_{t}\left(c_{t-1}+k_{t}\right)+m_{t}-p_{t-1} k_{t-1}-m_{t-1} \geq p_{t}\left(c_{t}+k_{t+1}\right)+m_{t+1}-p_{t-1} k_{t}-m_{t} .
\end{aligned}
$$

By re-arranging and using the fact that $\left\{k_{t}, m_{t}, c_{t}\right\}$ is egalitarian (so that $c_{t}=c_{t-1}$ for all $t \geq 1$ ), we have that:

$$
\begin{aligned}
& L_{t}=p_{t+1}\left(k_{t+1}-k_{t}\right)+\left(m_{t+1}-m_{t}\right) \geq p_{t}\left(k_{t}-k_{t-1}\right)+\left(m_{t}-m_{t-1}\right)=L_{t-1}, \\
& E_{t}=p_{t}\left(k_{t+1}-k_{t}\right)+\left(m_{t+1}-m_{t}\right) \leq p_{t-1}\left(k_{t}-k_{t-1}\right)+\left(m_{t}-m_{t-1}\right)=E_{t-1}
\end{aligned}
$$

hold for all $t \geq 1$. By (3) and (5), the value of net investments, $L_{t}$, measured in late pricing is non-positive and non-decreasing. Likewise, by (4) and (6), the value of net investments, $E_{t}$, measured in early pricing is nonnegative and non-increasing.

By Corollaries 1 and 2 , the price sequence $\left\{p_{t}\right\}$ is decreasing and the capital sequence $\left\{k_{t}\right\}$ is increasing, implying that, at any $t \geq 0$,

$$
E_{t}-L_{t}=\left(p_{t}-p_{t+1}\right)\left(k_{t+1}-k_{t}\right)>0,
$$

so that the two measures differ for all $t \geq 0$.

Since, for all $t \geq 0, L_{t}$ is non-positive and non-decreasing and $E_{t}$ is nonnegative and non-increasing, it follows that the limits, $L=\lim _{t \rightarrow \infty} L_{t}$ and $E=\lim _{t \rightarrow \infty} E_{t}$, 
exist, and furthermore, $L \leq 0 \leq E$. Hence, to show that $L=0=E$, it is sufficient to show that $E \leq L$, or equivalently, by (7):

$$
\lim _{t \rightarrow \infty} p_{t}\left(k_{t+1}-k_{t}\right) \leq \lim _{t \rightarrow \infty} p_{t+1}\left(k_{t+1}-k_{t}\right) .
$$

Using Corollary 2 and (P) and writing $r_{t}=m_{t}-m_{t+1}$, we have:

$$
p_{t}\left(k_{t+1}-k_{t}\right)=p_{t+1}\left(G_{k}\left(k_{t}, r_{t}\right)+1\right)\left(k_{t+1}-k_{t}\right) \leq p_{t+1}\left(\frac{G\left(k_{t}, r_{t}\right)}{k_{t}}+1\right)\left(k_{t+1}-k_{t}\right)
$$

for all $t \geq 0$, by (G1) and (G2). Hence, by (8), $E \leq L$ is established by showing:

$$
\lim _{t \rightarrow \infty} \frac{G\left(k_{t}, r_{t}\right)}{k_{t}}=0
$$

To show this, the following claim is helpful.

Claim $\lim _{t \rightarrow \infty} k_{t}=\infty$. Suppose the claim is not true. Then, by Corollary 2 , there exists $\bar{k}>0$ such that $k_{t} \leq \bar{k}$ for all $t \geq 0$ and, by (G1):

$$
c_{t} \leq G\left(k_{t}, m_{t}-m_{t+1}\right)+k_{t}-k_{t+1}<G\left(k_{t}, m_{t}-m_{t+1}\right) \leq G\left(\bar{k}, m_{t}\right) .
$$

We have $\lim _{t \rightarrow \infty} G\left(\bar{k}, m_{t}\right)=0$ by (G1) and (G2), as $\lim _{t \rightarrow \infty} m_{t}=0$ by Proposition 2 . By (10), this contradicts that $c_{t}=c>0$ for all $t \geq 0$.

By the claim, we may choose $s \geq 0$ such that $k_{t} \geq 1$ for all $t \geq s$, implying that

$$
\frac{G\left(k_{t}, r_{t}\right)}{k_{t}} \leq G\left(1, r_{t} / k_{t}\right) \leq G\left(1, r_{t}\right)=G\left(1, m_{t}-m_{t+1}\right) \leq G\left(1, m_{t}\right)
$$

for all $t \geq s$, by (G1). We have $\lim _{t \rightarrow \infty} G\left(1, m_{t}\right)=0$ by (G1) and (G2), as $\lim _{t \rightarrow \infty} m_{t}=0$ by Proposition 2. This shows (9).

For the sake of completeness, we state the following result, using the style of proof in Mitra et al. (2013, Proposition 5).

Proposition 4 Under $(G 1)-(G 3)$ and $(E)$, the efficient and egalitarian path $\left\{k_{t}, m_{t}\right.$, $\left.c_{t}\right\}$ from $(k, m) \in \Omega$ with $c_{t}=c>0$ for all $t \geq 0$ satisfies the capital-value transversality condition.

It is noteworthy that the capital-value transversality condition obtains without imposing an assumption that resource use be "important" (in the sense of (A4) or (A4') of Dasgupta and Mitra 1983).

Say that an interior and competitive path $\left\{k_{t}^{\prime}, m_{t}^{\prime}, c_{t}^{\prime}\right\}$ from $\left(k^{\prime}, m^{\prime}\right) \in \mathbb{R}_{+}^{2}$ has finite consumption value if the associated price sequence $\left\{p_{t}\right\}$ determined by $(\mathrm{P})$ satisfies $\sum_{t=0}^{\infty} p_{t+1} c_{t}^{\prime}<\infty$. This is equivalent to $\sum_{t=0}^{\infty} p_{t+1}<\infty$ if $c_{t}^{\prime}=c>0$ for all $t \geq 0$. As defined by Burmeister and Hammond (1977) and Dixit et al. (1980) in continuous time, an interior and competitive path is a regular maximin path if it

(a) is egalitarian, 
(b) has finite consumption value, and

(c) satisfies the capital-value transversality condition and resource exhaustion.

By Propositions 2 and 4, we have established that, under (G1)-(G3) and (E), the efficient and egalitarian path $\left\{k_{t}, m_{t}, c_{t}\right\}$ from $(k, m) \in \Omega$ with $c_{t}=c>0$ for all $t \geq 0$ satisfies (a) and (c). However, we cannot show, based on these assumptions, that $\left\{k_{t}, m_{t}, c_{t}\right\}$ has finite consumption value. The failure of (b) might arise if an increase in the initial resource stock beyond $m$ cannot be turned into a uniform increase in consumption; see Mitra et al. (2013, Theorem 2) for an investigation of this possibility in the continuous-time DHS model. ${ }^{2}$

Theorem 1 can be generalized to any model with multiple capital/consumption goods where the transformation of the capital vector $\mathbf{k}=\left(k_{1}, \ldots, k_{n}\right)$ to a gross output vector $\mathbf{y}=\left(y_{1}, \ldots, y_{n}\right)$ satisfies that $(\mathbf{k}, \mathbf{y})$ is in some $2 n$-dimensional set $\mathcal{T}$ and where, for each $t \geq 0$, consumption $\mathbf{c}_{t}$ equals $\mathbf{y}_{t}-\mathbf{k}_{t+1}$. However, this presupposes that any efficient path $\left\{\mathbf{k}_{t}, \mathbf{c}_{t}\right\}$ for which the utility $u\left(\mathbf{c}_{t}\right)$ derived from $\mathbf{c}_{t}$ is constant and equal to $u$ for all $t \geq 0$ has the following properties.

(i) $\left\{\mathbf{k}_{t}, \mathbf{c}_{t}\right\}$ is competitive with associated sequences of utility discount factors $\left\{\mu_{t}\right\}$ and present-value capital prices $\left\{\mathbf{p}_{t}\right\}$ so that, for all $t \geq 0$, we have:

$$
\begin{aligned}
& \mu_{t} u\left(\mathbf{c}_{t}\right)-\mathbf{p}_{t+1} \mathbf{c}_{t} \geq \mu_{t} u\left(\mathbf{c}^{\prime}\right)-\mathbf{p}_{t+1} \mathbf{c}^{\prime} \text { for all } \mathbf{c}^{\prime} \geq 0, \quad(\mathrm{C} u) \\
& \mathbf{p}_{t+1} \mathbf{y}_{t}-\mathbf{p}_{t} \mathbf{k}_{t} \geq \mathbf{p}_{t+1} \mathbf{y}^{\prime}-\mathbf{p}_{t} \mathbf{k}^{\prime} \text { for all }\left(\mathbf{k}^{\prime}, \mathbf{y}^{\prime}\right) \in \mathcal{T} . \quad(\mathrm{C} \pi)
\end{aligned}
$$

(ii) for each $t \geq 0, \mathbf{k}_{t}$ minimizes $\mathbf{p}_{t} \mathbf{k}^{\prime}$ over all vectors of stocks $\mathbf{k}^{\prime}$ that allow utility to be maintained at or above $u$ for all $s \geq t$.

Then it follows from (ii) that, for all $t \geq 0$,

$$
L_{t}=\mathbf{p}_{t+1}\left(\mathbf{k}_{t+1}-\mathbf{k}_{t}\right) \leq 0 \text { and } E_{t}=\mathbf{p}_{t}\left(\mathbf{k}_{t+1}-\mathbf{k}_{t}\right) \geq 0 .
$$

Hence, there exists $\lambda \in[0,1]$ such that $\left(\lambda \mathbf{p}_{t+1}+(1-\lambda) \mathbf{p}_{t}\right)\left(\mathbf{k}_{t+1}-\mathbf{k}_{t}\right)=0$, implying that Hartwick's rule is followed by a convex combination of early and late prices. Furthermore, for all $t \geq 1,-\mathbf{p}_{t+1} \mathbf{c}_{t} \geq-\mathbf{p}_{t+1} \mathbf{c}_{t-1}$ and $-\mathbf{p}_{t} \mathbf{c}_{t-1} \geq-\mathbf{p}_{t} \mathbf{c}_{t}$ by $(\mathrm{C} u)$ since $u\left(\mathbf{c}_{t}\right)=u\left(\mathbf{c}_{t-1}\right)$, and $\mathbf{p}_{t+1}\left(\mathbf{c}_{t}+\mathbf{k}_{t+1}\right)-\mathbf{p}_{t} \mathbf{k}_{t} \geq \mathbf{p}_{t+1}\left(\mathbf{c}_{t-1}+\mathbf{k}_{t}\right)-\mathbf{p}_{t} \mathbf{k}_{t-1}$ and $\mathbf{p}_{t}\left(\mathbf{c}_{t-1}+\mathbf{k}_{t}\right)-\mathbf{p}_{t-1} \mathbf{k}_{t-1} \geq \mathbf{p}_{t}\left(\mathbf{c}_{t}+\mathbf{k}_{t+1}\right)-\mathbf{p}_{t-1} \mathbf{k}_{t}$ by $(\mathrm{C} \pi)$. Therefore, for all $t \geq 1$,

$$
\begin{aligned}
& L_{t}=\mathbf{p}_{t+1}\left(\mathbf{k}_{t+1}-\mathbf{k}_{t}\right) \geq \mathbf{p}_{t}\left(\mathbf{k}_{t}-\mathbf{k}_{t-1}\right)=L_{t-1} \text { and } \\
& E_{t}=\mathbf{p}_{t}\left(\mathbf{k}_{t+1}-\mathbf{k}_{t}\right) \leq \mathbf{p}_{t-1}\left(\mathbf{k}_{t}-\mathbf{k}_{t-1}\right)=E_{t-1}
\end{aligned}
$$

by (2). Thus, results (3)-(6) are obtained also in this more general model, provided that properties (i) and (ii) can be established. Demonstrating under which conditions on $\mathcal{T}$ and $u(\cdot)$ these properties hold is beyond the scope of the present paper.

\footnotetext{
2 Mitra (1978) showed that an interior and efficient path has finite consumption value if resource use has a functional share of output that is bounded away from zero. Hence, under this additional assumption, an efficient and egalitarian path with $c_{t}=c>0$ for all $t \geq 0$ would satisfy (b).
} 


\section{Concluding remarks}

We have shown how the converse of Hartwick's result obtains in a discrete-time version of the Dasgupta-Heal-Solow model of capital accumulation and resource depletion under weak assumptions on the technology. We have established this result under the proviso that the valuation of net investments is made using a valuation rule that is intermediate between early and late pricing.

In the continuous-time DHS model, early and late pricing coincides and, as shown by Mitra (2002) in a general continuous-time model, the converse of Hartwick's rule holds as an exact result: If there exists an efficient and egalitarian path $(k(\tau), m(\tau), c(\tau))$ from $(k, m) \in \mathbb{R}_{++}^{2}$, then the path is interior and competitive at associated prices $(p(\tau), q(\tau))$. Furthermore, $q(\tau)$ is a positive constant which can be normalized to $1, p(\tau)>0$ decreases as $\tau$ increases, $\dot{k}(\tau)>0$ for $\tau \geq 0$, and:

$$
p(\tau) \dot{k}(\tau)+\dot{m}(\tau)=0 \quad \text { for all } \tau \geq 0 .
$$

Let $t \in\{0,1,2, \ldots\}$. Since $\dot{k}(\tau)>0$ for all $\tau \geq 0$, it is possible to define $p$ as the weighted mean of the competitive capital prices in the interval $[t, t+1]$, where the weights are given by the rates of capital investment:

$$
p=\frac{\int_{t}^{t+1} p(\tau) \dot{k}(\tau) \mathrm{d} \tau}{\int_{t}^{t+1} \dot{k}(\tau) \mathrm{d} \tau} .
$$

Then, by using (11) and noting that $\int_{t}^{t+1} \dot{k}(\tau) \mathrm{d} \tau=k(t+1)-k(t)$ and $\int_{t}^{t+1} \dot{m}(\tau) \mathrm{d} \tau=m(t+1)-m(t)$, we obtain:

$$
p(k(t+1)-k(t))+(m(t+1)-m(t))=\int_{t}^{t+1}(p(\tau) \dot{k}(\tau)+\dot{m}(\tau)) \mathrm{d} \tau=0 .
$$

Thus, our discrete-time converse of Hartwick's result holds when $p$ in (13) is precisely the weighted mean of the competitive prices in the interval $[t, t+1]$, as given by (12). Furthermore, since $p(\tau)$ is decreasing in $\tau$, we will have $p \in[p(t+1), p(t)]$. Finally, the mean value theorem of integral calculus will ensure (under continuity of the functions $p(\tau)$ and $\dot{k}(\tau))$ that there is in fact a point of time $s \in[t, t+1]$ such that the competitive price at $s, p(s)$, equals $p$ as given by (12).

The question remains whether some variant of Hartwick's result can established in the discrete-time setting: Is it the case that if along an efficient path Hartwick's rule is followed forever, then an egalitarian path will be implemented?

If the efficient path is interior (so that capital and resource use are positive in each time period), then it follows by the proof of Proposition 2 and Corollary 3 that the path is competitive. Therefore, we obtain the following analogs to (5) and (6) for a path that is not necessarily egalitarian:

$$
\begin{gathered}
p_{t+1}\left(c_{t}-c_{t-1}\right)+\left(L_{t}-L_{t-1}\right) \geq 0 \\
p_{t}\left(c_{t}-c_{t-1}\right)+\left(E_{t}-E_{t-1}\right) \leq 0
\end{gathered}
$$


Thus, keeping the value of net investments constant in the present-value prices determined by $(\mathrm{P})$ leads to non-increasing consumption if early pricing is applied, and non-decreasing consumption if late pricing is applied. The latter result can be rephrased as saying that keeping the value of net investments constant in terms of late pricing ensures "sustained development," as defined by Pezzey (1997). Keeping the value of net investments in present-value prices constant (but not necessarily equal to zero) corresponds to the so-called Dixit-Hammond-Hoel rule (Dixit et al. 1980).

One can now proceed to show that keeping the value of net investments in early pricing constant and negative forever contradicts feasibility of the path, and investigate the assumptions under which keeping the value of net investments in late pricing constant and positive forever contradicts efficiency of the path. However, as we have seen from the main result of this paper, even though an efficient and egalitarian path is characterized by a nonnegative competitive value of net investments in early pricing and a non-positive competitive value of net investments in late pricing, these measures of net investments will not remain constant. Rather, a mixture of these measures, determined by the efficient and egalitarian path and being specific to each time period, remains constant and equal to zero in each time period.

Thus, neither the value of net investments in early pricing nor the value of net investments in late pricing value can be used to steer the economy along a path that is exactly egalitarian. In addition, there is the problem that appears also in the continuous-time setting of determining the initial rate of resource use, so that the egalitarian path exhausts the resource precisely in the limit when time is approaching infinity. Clearly, exhaustion in finite time would lead to infeasibility, while letting part of the resource stock which remains unutilized would lead to inefficiency.

Hence, the problems that arise also in continuous time-limiting the applicability of Hartwick's rule as a prescriptive rule for sustainability-remains also in the discrete-time setting. In addition, with discrete time, as we have seen from the main result of this paper, the exact relative price between capital and resource to be applied in each time period is derived from the efficient and egalitarian path. Thus, in discrete time it seems challenging to use Hartwick's rule to steer the economy along an efficient and egalitarian path.

Acknowledgements Thanks go to two anonymous reviewers for insightful comments, Wolfgang Buchholz, John Hartwick and Vincent Martinet for helpful discussions, and participants at SURED 2018, the 25th Ulvön Conference on Environmental Economics, and a seminar at l'Université du Québec à Montréal for useful remarks. This paper is part of the research activities at the Centre for the Study of Equality, Social Organization, and Performance (ESOP) at the Department of Economics at the University of Oslo. Asheim's research has benefitted from stays at IMéRA-Marseille, CIREQ-Montréal, and Paris School of Economics.

Funding Open access funding provided by Oslo University \& Oslo University Hospital

Availability of data and materials (data transparency) Not applicable.

\section{Compliance with ethical standards}

Conflict of interest Asheim declares no conflicts of interest and no competing interests. Mitra is deceased; 
Asheim does not know of any conflicts of interest or any competing interests in his case.

Code availability (software application or custom code) Not applicable.

Open Access This article is licensed under a Creative Commons Attribution 4.0 International License, which permits use, sharing, adaptation, distribution and reproduction in any medium or format, as long as you give appropriate credit to the original author(s) and the source, provide a link to the Creative Commons licence, and indicate if changes were made. The images or other third party material in this article are included in the article's Creative Commons licence, unless indicated otherwise in a credit line to the material. If material is not included in the article's Creative Commons licence and your intended use is not permitted by statutory regulation or exceeds the permitted use, you will need to obtain permission directly from the copyright holder. To view a copy of this licence, visit http://creativecommons.org/licen ses/by/4.0/.

\section{Appendix: Proofs}

Proof of Lemma 1 (a) Assume that $\left\{k_{t}, m_{t}, c_{t}\right\}$ is non-wasteful and satisfies Hotelling's rule. Let $t \geq 0$ be an arbitrary time period and let $\left((k, m),\left(y, m^{\prime}\right)\right) \in \mathcal{T}$. Then, denoting $m-m^{\prime}$ by $r$ and $m_{t}-m_{t+1}$ by $r_{t}$, we have $r \geq 0$ and:

$$
\begin{aligned}
y-y_{t} & \leq\left(G\left(k, m-m^{\prime}\right)+k\right)-\left(G\left(k_{t}, m_{t}-m_{t+1}\right)+k_{t}\right) \\
& \leq\left(G_{k}\left(k_{t}, r_{t}\right)+1\right)\left(k-k_{t}\right)+G_{r}\left(k_{t}, r_{t}\right)\left(r-r_{t}\right),
\end{aligned}
$$

where we have used non-wastefulness of $\left\{k_{t}, m_{t}, c_{t}\right\}$ in the first line of (16), and (G1) and (G3) in the second line of (16).

Dividing through in (16) by $G_{r}\left(k_{t}, r_{t}\right)$ and using $(\mathrm{H})$ and $(\mathrm{P})$, we get:

$$
\begin{aligned}
p_{t+1}\left(y-y_{t}\right)=\frac{1}{G_{r}\left(k_{t}, r_{t}\right)}\left(y-y_{t}\right) & \leq\left(\frac{G_{k}\left(k_{t}, r_{t}\right)+1}{G_{r}\left(k_{t}, r_{t}\right)}\right)\left(k-k_{t}\right)+\left(r-r_{t}\right) \\
& =p_{t}\left(k-k_{t}\right)+q_{t}\left(r-r_{t}\right) .
\end{aligned}
$$

Transposing terms in (17), we obtain that (C) is satisfied:

$$
p_{t+1} y_{t}+q_{t+1} m_{t+1}-p_{t} k_{t}-q_{t} m_{t} \geq p_{t+1} y+q_{t+1} m^{\prime}-p_{t} k-q_{t} m .
$$

(b) Assume that $\left\{k_{t}, m_{t}, c_{t}\right\}$ is competitive with associated non-null sequence $\left\{p_{t}, q_{t}\right\}$ of nonnegative price pairs.

First, we establish that $q_{t+1}=q_{t}$ for all $t \geq 0$. To show this, note that

$$
\left((k, m),\left(y, m^{\prime}\right)\right)=\left(\left(k_{t}, m_{t}+\varepsilon\right),\left(G\left(k_{t}, m_{t}-m_{t+1}\right)+k_{t}, m_{t+1}+\varepsilon\right)\right) \in \mathcal{T}
$$

for all $\varepsilon \geq-m_{t+1}(<0)$, where $t \geq 0$ is an arbitrary time period. Furthermore,

$$
\left(p_{t+1} y+q_{t+1} m^{\prime}-p_{t} k-q_{t} m\right)-\left(p_{t+1} y_{t}+q_{t+1} m_{t+1}-p_{t} k_{t}-q_{t} m_{t}\right) \geq\left(q_{t+1}-q_{t}\right) \varepsilon,
$$

where the inequality might be strict if $\left\{k_{t}, m_{t}, c_{t}\right\}$ is not non-wasteful. By choosing $\varepsilon>0$, the competitiveness of $\left\{k_{t}, m_{t}, c_{t}\right\}$ is contradicted if $q_{t+1}>q_{t}$. And likewise, 
by choosing $\varepsilon<0$, the competitiveness of $\left\{k_{t}, m_{t}, c_{t}\right\}$ is contradicted if $q_{t+1}<q_{t}$. Hence, $q_{t}=q \geq 0$ for all $t \geq 0$.

Second, we observe that

$$
p_{t+1} y_{t}=p_{t+1}\left(G\left(k_{t}, m_{t}-m_{t+1}\right)+k_{t}\right) \quad \text { for all } t \geq 0,
$$

since $p_{t+1} y_{t}>p_{t+1}\left(G\left(k_{t}, m_{t}-m_{t+1}\right)+k_{t}\right)$ is infeasible and $p_{t+1} y_{t}<p_{t+1}\left(G\left(k_{t}\right.\right.$, $\left.\left.m_{t}-m_{t+1}\right)+k_{t}\right)$ would contract the competitiveness of $\left\{k_{t}, m_{t}, c_{t}\right\}$ as

$$
\left((k, m),\left(y, m^{\prime}\right)\right)=\left(\left(k_{t}, m_{t}\right),\left(G\left(k_{t}, m_{t}-m_{t+1}\right)+k_{t}, m_{t+1}\right)\right) \in \mathcal{T} .
$$

Denoting $m-m^{\prime}$ by $r$ and $m_{t}-m_{t+1}$ by $r_{t}$, it follows from (18) and the competitiveness of $\left\{k_{t}, m_{t}, c_{t}\right\}$ that, for all $t \geq 0$ :

$$
\begin{array}{r}
p_{t+1}\left(G\left(k_{t}, r_{t}\right)+k_{t}\right)-p_{t} k_{t}-q r_{t} \geq p_{t+1}(G(k, r)+k)-p_{t} k-q r \\
\quad \text { for all }(k, r) \in \mathbb{R}_{+}^{2} .
\end{array}
$$

Since the path $\left\{k_{t}, m_{t}, c_{t}\right\}$ is interior, we have that $\left(k_{t}, r_{t}\right) \in \mathbb{R}_{++}^{2}$ for all $t \geq 0$. The first-order conditions for the maximization in (19) imply:

$$
\begin{gathered}
p_{t+1}\left(G_{k}\left(k_{t}, r_{t}\right)+1\right)=p_{t} \quad \text { for all } t \geq 0, \\
p_{t+1} G_{r}\left(k_{t}, r_{t}\right)=q \quad \text { for all } t \geq 0 .
\end{gathered}
$$

If $q=0$, then (21) implies that $p_{t+1}=0$ for all $t \geq 0$ (by using (G3)), and $p_{0}=0$ by (20). However, this contradicts the fact that the sequence $\left\{p_{t}, q_{t}\right\}$ is non-null. Thus, $q>0$, and we normalize by letting $q=1$. Furthermore, it follows from (20) and (21) that $\left\{p_{t}, q_{t}\right\}$ is given by $(\mathrm{P})$ and that this sequence is unique up to a positive linear transformation. In particular, $p_{t}>0$ for all $t \geq 0$ (using (G3)), implying that nonwastefulness follows directly from (18). Finally, (20) and (21) imply that

$$
\frac{G_{r}\left(k_{t+1}, r_{t+1}\right)}{G_{r}\left(k_{t}, r_{t}\right)}=\frac{p_{t+1}}{p_{t+2}}=G_{k}\left(k_{t+1}, r_{t+1}\right)+1 \quad \text { for all } t \geq 0,
$$

showing that $(\mathrm{H})$ holds.

Proof of Corollary 1 We have that the price sequence $\left\{p_{t}\right\}$ is decreasing since

$$
\frac{p_{t}}{p_{t+1}}=G_{k}\left(k_{t}, m_{t}-m_{t+1}\right)+1>1 \text { for all } t \geq 0
$$

by (20) and (G3) and the fact that $\left\{k_{t}, m_{t}, c_{t}\right\}$ is interior.

Proof of Lemma 2 Fix an arbitrary $t \geq 0$.

Assume that there exists $\left\{k_{\tau}^{\prime}, m_{\tau}^{\prime}, c_{\tau}^{\prime}\right\} \in \mathcal{F}\left(k^{\prime}, m^{\prime}\right)$ with $c_{\tau}^{\prime} \geq c$ for all $\tau \geq 0$, where $k^{\prime}<k_{t}$ and $m^{\prime} \leq m_{t}$. Construct $\left\{k_{\tau}^{\prime \prime}, m_{\tau}^{\prime \prime}, c_{\tau}^{\prime \prime}\right\} \in \mathcal{F}\left(k_{t}, m_{t}\right)$ by letting 


$$
\begin{aligned}
& \left(k_{0}^{\prime \prime}, m_{0}^{\prime \prime}, c_{0}^{\prime \prime}\right)=\left(k_{t}, m_{t}, G\left(k_{t}, m_{t}-m_{1}^{\prime}\right)+k_{t}-k_{1}^{\prime}\right), \\
& \left(k_{\tau}^{\prime \prime}, m_{\tau}^{\prime \prime}, c_{\tau}^{\prime \prime}\right)=\left(k_{\tau}^{\prime}, m_{\tau}^{\prime}, c_{\tau}^{\prime}\right) \quad \text { for } \tau \geq 1 .
\end{aligned}
$$

It follows from (G1) that $c_{0}^{\prime \prime}=G\left(k_{t}, m_{t}-m_{1}^{\prime}\right)+k_{t}-k_{1}^{\prime}>G\left(k^{\prime}, m^{\prime}-m_{1}^{\prime}\right)+k^{\prime}-k_{1}^{\prime}$ $\geq c_{0}^{\prime} \geq c=c_{t}$, since $k^{\prime}<k_{t}$ and $m^{\prime} \leq m_{t}$, while $c_{\tau}^{\prime \prime}=c_{\tau}^{\prime} \geq c=c_{t+\tau}$ for all $\tau \geq 1$. This contradicts the fact that $\left\{k_{t}, m_{t}, c_{t}\right\}$ is efficient.

Next, assume that there exists $\left\{k_{\tau}^{\prime}, m_{\tau}^{\prime}, c_{\tau}^{\prime}\right\} \in \mathcal{F}\left(k^{\prime}, m^{\prime}\right)$ with $c_{\tau}^{\prime} \geq c$ for all $t \geq 0$, where $k^{\prime} \leq k_{t}$ and $m^{\prime}<m_{t}$. By $(\mathrm{G} 2), k^{\prime}>0$, since otherwise $c_{\tau}^{\prime}=0<c$ for all $t \geq 0$. Construct $\left\{k_{\tau}^{\prime \prime}, m_{\tau}^{\prime \prime}, c_{\tau}^{\prime \prime}\right\} \in \mathcal{F}\left(k_{t}, m_{t}\right)$ by letting

$$
\begin{aligned}
& \left(k_{0}^{\prime \prime}, m_{0}^{\prime \prime}, c_{0}^{\prime \prime}\right)=\left(k_{t}, m_{t}, G\left(k_{t}, m_{t}-m_{1}^{\prime}\right)+k_{t}-k_{1}^{\prime}\right), \\
& \left(k_{\tau}^{\prime \prime}, m_{\tau}^{\prime \prime}, c_{\tau}^{\prime \prime}\right)=\left(k_{\tau}^{\prime}, m_{\tau}^{\prime}, c_{\tau}^{\prime}\right) \quad \text { for } \tau \geq 1 .
\end{aligned}
$$

It follows from (G3) that $c_{0}^{\prime \prime}=G\left(k_{t}, m_{t}-m_{1}^{\prime}\right)+k_{t}-k_{1}^{\prime}>G\left(k^{\prime}, m^{\prime}-m_{1}^{\prime}\right)+k^{\prime}-k_{1}^{\prime}$ $\geq c_{0}^{\prime} \geq c=c_{t}$, since $k^{\prime} \leq k_{t}$ and $m^{\prime}<m_{t}$, while $c_{\tau}^{\prime \prime}=c_{\tau}^{\prime} \geq c=c_{t+\tau}$ for all $\tau \geq 1$. This contradicts the fact that $\left\{k_{t}, m_{t}, c_{t}\right\}$ is efficient.

Proof of Corollary 2 Since by feasibility we have $m_{t+1} \leq m_{t}$, it follows from Lemma 2 that $k_{t+1} \geq k_{t}$, and consequently $G\left(k_{t}, m_{t}-m_{t+1}\right) \geq c>0$. By (G2), we must have $k_{t}>0$ and $m_{t}>m_{t+1}$, so that $\left\{k_{t}, m_{t}, c_{t}\right\}$ is interior. Furthermore, by Lemma 2, $k_{t+1}=k_{t}$ is ruled out, so we must have $k_{t+1}>k_{t}$.

Proof of Lemma 3 Assume that $\left(k^{\prime}, m^{\prime}\right)$ and $\left(k^{\prime \prime}, m^{\prime \prime}\right)$ are both in $S(c)$. Hence, there exist $\left\{k_{t}^{\prime}, m_{t}^{\prime}, c_{t}^{\prime}\right\} \in \mathcal{F}\left(k^{\prime}, m^{\prime}\right)$ with $c_{t}^{\prime} \geq c$ for all $t \geq 0$ and $\left\{k_{t}^{\prime \prime}, m_{t}^{\prime \prime}, c_{t}^{\prime \prime}\right\} \in \mathcal{F}\left(k^{\prime \prime}, m^{\prime \prime}\right)$ with $c_{t}^{\prime \prime} \geq c$ for all $t \geq 0$. Let $\lambda \in(0,1)$, and define $\left\{k_{t}^{\prime \prime \prime}, m_{t}^{\prime \prime \prime}, c_{t}^{\prime \prime \prime}\right\}$ for all $t \geq 0$ by

$$
\begin{aligned}
k_{t}^{\prime \prime \prime} & =\lambda k_{t}^{\prime}+(1-\lambda) k_{t}^{\prime \prime}, \\
m_{t}^{\prime \prime \prime} & =\lambda m_{t}^{\prime}+(1-\lambda) m_{t}^{\prime \prime}, \\
c_{t}^{\prime \prime \prime} & =\lambda c_{t}^{\prime}+(1-\lambda) c_{t}^{\prime \prime} .
\end{aligned}
$$

Since $c_{t}^{\prime \prime \prime}=\lambda c_{t}^{\prime}+(1-\lambda) c_{t}^{\prime \prime} \geq \lambda c+(1-\lambda) c=c$ for all $t \geq 0$, it suffices to show that $c_{t}^{\prime \prime \prime}+k_{t+1}^{\prime \prime \prime} \leq G\left(k_{t}^{\prime \prime \prime}, m_{t}^{\prime \prime \prime}-m_{t+1}^{\prime \prime \prime}\right)+k_{t}^{\prime \prime \prime}$ for all $t \geq 0$. This holds since:

$$
\begin{aligned}
c_{t}^{\prime \prime \prime} & +k_{t+1}^{\prime \prime \prime}=\lambda\left(c_{t}^{\prime}+k_{t+1}^{\prime}\right)+(1-\lambda)\left(c_{t}^{\prime \prime}+k_{t+1}^{\prime \prime}\right) \\
& \leq \lambda\left(G\left(k_{t}^{\prime}, m_{t}^{\prime}-m_{t+1}^{\prime}\right)+k_{t}^{\prime}\right)+(1-\lambda)\left(G\left(k_{t}^{\prime \prime}, m_{t}^{\prime \prime}-m_{t+1}^{\prime \prime}\right)+k_{t}^{\prime \prime}\right) \\
& \leq G\left(\lambda k_{t}^{\prime}+(1-\lambda) k_{t}^{\prime \prime}, \lambda\left(m_{t}^{\prime}-m_{t+1}^{\prime}\right)+(1-\lambda)\left(m_{t}^{\prime \prime}-m_{t+1}^{\prime \prime}\right)\right)+\lambda k_{t}^{\prime}+(1-\lambda) k_{t}^{\prime \prime} \\
& =G\left(k_{t}^{\prime \prime \prime}, m_{t}^{\prime \prime \prime}-m_{t+1}^{\prime \prime \prime}\right)+k_{t}^{\prime \prime \prime},
\end{aligned}
$$

where the second inequality follows since, by (G1), $G$ is concave.

Proof of Proposition 1 Fix an arbitrary $t \geq 0$ and define:

$$
D=\left\{\left(k^{\prime \prime}-k^{\prime}, m^{\prime \prime}-m^{\prime}\right):\left(k^{\prime \prime}, m^{\prime \prime}\right) \in R_{t} \text { and }\left(k^{\prime}, m^{\prime}\right) \in S(c)\right\} .
$$

Clearly, $R_{t}$ is a convex subset of $\mathbb{R}^{2}$, and since $S(c)$ is a convex subset of $\mathbb{R}^{2}$ by Lemma 3 , so is $D$. Suppose $D \cap \mathbb{R}_{++}^{2} \neq \emptyset$. Then there would exist $\left(k^{\prime \prime}, m^{\prime \prime}\right) \in R_{t}$ and 
$\left(k^{\prime}, m^{\prime}\right) \in S(c)$ such that $\left(k^{\prime \prime}, m^{\prime \prime}\right) \gg\left(k^{\prime}, m^{\prime}\right)$. Since $\left(k^{\prime \prime}, m^{\prime \prime}\right) \leq\left(k_{t}, m_{t}\right)$, this means there would exist $\left(k^{\prime}, m^{\prime}\right) \in S(c)$ with $\left(k^{\prime}, m^{\prime}\right) \ll\left(k_{t}, m_{t}\right)$, which is impossible by Lemma 2. Thus, we can apply the separation theorem 3.5 in Nikaido (1968, p. 35) to assert that there exists $\left(P_{t}, Q_{t}\right) \in \mathbb{R}_{+}^{2}$, with $\left(P_{t}, Q_{t}\right)$ non-null, such that:

$$
P_{t} \tilde{k}+Q_{t} \tilde{m} \leq 0 \quad \text { for all }(\tilde{k}, \tilde{m}) \in D \text {. }
$$

This means that for all $\left(k^{\prime \prime}, m^{\prime \prime}\right) \in R_{t}$ and $\left(k^{\prime}, m^{\prime}\right) \in S(c)$, we must have:

$$
P_{t}\left(k^{\prime \prime}-k^{\prime}\right)+Q_{t}\left(m^{\prime \prime}-m^{\prime}\right) \leq 0 .
$$

Since $\left(k_{t}, m_{t}\right) \in R(t)$, we must have:

$$
P_{t} k_{t}+Q_{t} m_{t} \leq P_{t} k^{\prime}+Q_{t} m^{\prime} \quad \text { for all }\left(k^{\prime}, m^{\prime}\right) \in S(c) .
$$

This establishes the proposition.

Proof of Proposition 2 If $c_{s}+k_{s+1}<G\left(k_{s}, m_{s}-m_{s+1}\right)+k_{s}$ for some $s \geq 0$, then consumption can be increased at time $s$ without changing consumption at any other time $t \geq 0$. This contradicts the fact that $\left\{k_{t}, m_{t}, c_{t}\right\}$ is efficient. Hence, $c_{s}+k_{t+1}=G\left(k_{t}, m_{t}-m_{t+1}\right)+k_{t}$ for all $t \geq 0$, showing that $\left\{k_{t}, m_{t}, c_{t}\right\}$ is non-wasteful.

Since $m_{t}$ is non-increasing in $t$, and nonnegative, the sequence $\left\{m_{t}\right\}$ has a nonnegative limit: $\lim _{t \rightarrow \infty} m_{t} \geq 0$. Suppose $\lim _{t \rightarrow \infty} m_{t}>0$. Then resource use can be increased at some time $s \geq 0$ without changing resource use at any other time $t \geq 0$. By (G3) and the fact that $\left\{k_{t}, m_{t}, c_{t}\right\}$ is interior, production and therefore consumption can be increased at time $s$, without changing consumption at any other time $t \geq 0$; this contradicts the fact that $\left\{k_{t}, m_{t}, c_{t}\right\}$ is efficient. Hence, we must have $\lim _{t \rightarrow \infty} m_{t}=0$, showing that $\left\{k_{t}, m_{t}, c_{t}\right\}$ satisfies resource exhaustion.

By Corollary $2,\left\{k_{t}, m_{t}, c_{t}\right\}$ is interior, so it only remains to show that $(\mathrm{H})$ holds. Fix an arbitrary $t \geq 0$. Denote $m_{t}-m_{t+1}$ by $r_{t}$ and $m_{t+1}-m_{t+2}$ by $r_{t+1}$. The triple $\left(k_{t+1}, r_{t}, r_{t+1}\right)$ clearly minimizes the sum $r_{t}^{\prime}+r_{t+1}^{\prime}$ of resource use in time periods $t$ and $t+1$ over all triples $\left(k_{t+1}^{\prime}, r_{t}^{\prime}, r_{t+1}^{\prime}\right) \gg 0$ that satisfy the set of constraints:

$$
\left.\begin{array}{l}
c+k_{t+1}^{\prime} \leq G\left(k_{t}, r_{t}^{\prime}\right)+k_{t}, \\
c+k_{t+2} \leq G\left(k_{t+1}^{\prime}, r_{t+1}^{\prime}\right)+k_{t+1}^{\prime} \cdot
\end{array}\right\}
$$

For if there is a triple $\left(k_{t+1}^{\prime}, r_{t}^{\prime}, r_{t+1}^{\prime}\right) \gg 0$ which satisfies this set of constraints, and $\varepsilon:=\left(r_{t}+r_{t+1}\right)-\left(r_{t}^{\prime}+r_{t+1}^{\prime}\right)>0$, then $(k, m-\varepsilon) \in S(c)$, and this has been shown to be impossible by Lemma 2 .

Clearly, $\left(k_{t+1}, r_{t}, r_{t+1}\right) \gg 0$ satisfies each of the constraints in this set with equality (since $\left\{k_{t}, m_{t}, c_{t}\right\}$ is non-wasteful). Therefore, $\left(k_{t+1}^{\prime}, r_{t}^{\prime}, r_{t+1}^{\prime}\right):=\left(k_{t+1}, r_{t}+\theta, r_{t+1}+\theta\right)$ satisfies each of the constraints with strict inequality (by (G3)), so that Slater's condition is satisfied. Since $G$ is concave (by (G1)), we can invoke the version of the Kuhn-Tucker theorem due to Arrow et al. (1961) to assert that there exist $\left(p_{t+1}, p_{t+2}\right) \in \mathbb{R}_{+}^{2}$ such that the following first-order conditions hold: 


$$
\begin{aligned}
& p_{t+2}\left(G_{k}\left(k_{t+1}, r_{t+1}\right)+1\right)=p_{t+1}, \\
& p_{t+1} G_{r}\left(k_{t}, r_{t}\right)=1, \\
& p_{t+2} G_{r}\left(k_{t+1}, r_{t+1}\right)=1 .
\end{aligned}
$$

Since $\left\{k_{t}, m_{t}, c_{t}\right\}$ is interior, we can use (G3) and the second and third equations above to infer that $\left(p_{t+1}, p_{t+2}\right) \in \mathbb{R}_{++}^{2}$. Now, the above set of equations yields:

$$
\frac{G_{r}\left(k_{t+1}, r_{t+1}\right)}{G_{r}\left(k_{t}, r_{t}\right)}=\frac{p_{t+1}}{p_{t+2}}=G_{k}\left(k_{t+1}, r_{t+1}\right)+1 .
$$

Since $t \geq 0$ is arbitrary, this establishes $(\mathrm{H})$.

Proof of Proposition 3 Fix an arbitrary $t \geq 0$. Define $X=\left\{\left(k^{\prime}, m^{\prime}\right) \in \mathbb{R}^{2}: k^{\prime}>0\right.$, $\left.m^{\prime}>m_{t+1}\right\}$, and let $x: X \rightarrow \mathbb{R}$ determine the excess of consumption in time period $t$ relative to $c$, if the stock vector $\left(k^{\prime}, m^{\prime}\right)$ at time $t$ is transformed to the stock vector $\left(k_{t+1}, m_{t+1}\right)$ at time $t+1$ in a non-wasteful manner:

$$
x\left(k^{\prime}, m^{\prime}\right)=\left(G\left(k^{\prime}, m^{\prime}-m_{t+1}\right)+k^{\prime}\right)-k_{t+1}-c .
$$

Then, $X$ is an open set in $\mathbb{R}^{2}$ and $x$ is continuously differentiable on $X$ (by (G3)). Furthermore, since $\left\{k_{t}, m_{t}, c_{t}\right\}$ is non-wasteful by Proposition 2, we have $x\left(k_{t}, m_{t}\right)=0$. Note that by interiority of $\left\{k_{t}, m_{t}, c_{t}\right\}$ and (G3),

$$
x_{m}\left(k_{t}, m_{t}\right)=G_{r}\left(k_{t}, m_{t}-m_{t+1}\right) \neq 0 .
$$

Hence, we can invoke the implicit function theorem (see Rudin 1976, Theorem 9.28, pp. 224-5) to assert that there is an open interval $A$ containing $k_{t}$, and a unique function $m: A \rightarrow \mathbb{R}$ which, for each $k^{\prime} \in A$, determines the smallest resource stock $m\left(k^{\prime}\right)=m^{\prime}$ enabling consumption to equal $c$ at time $t$ when $\left(k^{\prime}, m^{\prime}\right)$ at time $t$ is transformed to $\left(k_{t+1}, m_{t+1}\right)$ at time $t+1$. In effect, the function $m$ maps the frontier of the set $S_{t}(c)$, as defined by (2), in a neighborhood of $\left(k_{t}, m_{t}\right)$. We have:

(i) $\left(k^{\prime}, m\left(k^{\prime}\right)\right) \in X$ and $x\left(k^{\prime}, m\left(k^{\prime}\right)\right)=0$ for all $k^{\prime} \in A$,

(ii) $m\left(k_{t}\right)=m_{t}$,

(iii) $m$ is continuously differentiable on $A$.

Using (i) and (iii), we have: $x_{k}\left(k_{t}, m\left(k_{t}\right)\right)+x_{m}\left(k_{t}, m\left(k_{t}\right)\right) \cdot m^{\prime}\left(k_{t}\right)=0$. And, using (ii) and the definition of $x$, we obtain:

$$
\left(G_{k}\left(k_{t}, m_{t}-m_{t+1}\right)+1\right)+G_{r}\left(k_{t}, m_{t}-m_{t+1}\right) \cdot m^{\prime}\left(k_{t}\right)=0 .
$$

We obtain $\left(k^{\prime}, m\left(k^{\prime}\right)\right) \in S(c)$ for all $k^{\prime} \in A$ by combining (a) the property that, for each $k^{\prime} \in A, m\left(k^{\prime}\right)$ enables consumption to equal $c$ at time $t$ when $\left(k^{\prime}, m\left(k^{\prime}\right)\right)$ at time $t$ is transformed to $\left(k_{t+1}, m_{t+1}\right)$ at time $t+1$ with (b) the fact that $\left(k_{t+1}, m_{t+1}\right) \in S(c)$. Using Proposition 1, we can therefore write: 


$$
P_{t} k_{t}+Q_{t} m_{t} \leq P_{t} k^{\prime}+Q_{t} m\left(k^{\prime}\right) \text { for all } k^{\prime} \in A \text {. }
$$

Since $A$ is an open set, the following first-order condition must hold:

$$
P_{t}+Q_{t} m^{\prime}\left(k_{t}\right)=0
$$

which, using (22), yields:

$$
P_{t}=Q_{t} \cdot \frac{G_{k}\left(k_{t}, m_{t}-m_{t+1}\right)+1}{G_{r}\left(k_{t}, m_{t}-m_{t+1}\right)} .
$$

Thus, since $\left(P_{t}, Q_{t}\right)$ is non-null and nonnegative, we have $\left(P_{t}, Q_{t}\right) \in \mathbb{R}_{++}^{2}$ and:

$$
\frac{P_{t}}{Q_{t}}=\frac{G_{k}\left(k_{t}, m_{t}-m_{t+1}\right)+1}{G_{r}\left(k_{t}, m_{t}-m_{t+1}\right)}=p_{t}
$$

by $(\mathrm{P})$, thereby establishing the result.

Proof of Proposition 4 By Corollary 2, $\left\{k_{t}, m_{t}, c_{t}\right\}$ is interior. Hence, by (P), it remains to show that $\lim _{t \rightarrow \infty} p_{t} k_{t}=0$. We show this by first establishing an intermediate claim.

Claim: $\lim _{t \rightarrow \infty} p_{t}=0$. Let $t \geq 1$. Then:

$$
\begin{aligned}
p_{t}\left(k_{t}-k_{0}\right) & =p_{t} \sum_{\tau=0}^{t-1}\left(k_{\tau+1}-k_{\tau}\right)=\sum_{\tau=0}^{t-1} p_{t}\left(k_{\tau+1}-k_{\tau}\right) \\
& \leq \sum_{\tau=0}^{t-1} p_{\tau+1}\left(k_{\tau+1}-k_{\tau}\right) \leq \sum_{\tau=0}^{t-1}\left(m_{\tau}-m_{\tau+1}\right) \leq m_{0},
\end{aligned}
$$

where the first inequality follows since, by Corollaries 1 and 2 , the price sequence $\left\{p_{t}\right\}$ is decreasing and the capital sequence $\left\{k_{t}\right\}$ is increasing, and the second inequality follows from (3). Now, $\lim _{t \rightarrow \infty} p_{t}=0$ follows since, by the proof of Theorem 1 , $\lim _{t \rightarrow \infty} k_{t}=\infty$.

To establish $\lim _{t \rightarrow \infty} p_{t} k_{t}=0$, it is sufficient to show that, for all $\epsilon>0$, there exists $s^{\prime} \geq 0$ such that $p_{t} k_{t} \leq \varepsilon$ for all $t \geq s^{\prime}$. As $\lim _{t \rightarrow \infty} m_{t}=0$ by Proposition 2 , there exists $s \geq 0$ such that $m_{s} \leq \varepsilon / 2$. By the claim, there exists $s^{\prime}>s$ such that $p_{t} k_{s} \leq \varepsilon / 2$ for all $t \geq s^{\prime}$. Since, as in the claim,

$$
\begin{aligned}
p_{t}\left(k_{t}-k_{s}\right) & =p_{t} \sum_{\tau=s}^{t-1}\left(k_{\tau+1}-k_{\tau}\right)=\sum_{\tau=s}^{t-1} p_{t}\left(k_{\tau+1}-k_{\tau}\right) \\
& \leq \sum_{\tau=s}^{t-1} p_{\tau+1}\left(k_{\tau+1}-k_{\tau}\right) \leq \sum_{\tau=s}^{t-1}\left(m_{\tau}-m_{\tau+1}\right) \leq m_{s}
\end{aligned}
$$

for all $t>s$, it follows from the choice of $s$ and $s^{\prime}$ that

$$
p_{t} k_{t} \leq p_{t} k_{s}+m_{s} \leq \varepsilon / 2+\varepsilon / 2=\varepsilon
$$


for all $t \geq s^{\prime}$, thereby establishing the capital-value transversality condition.

\section{References}

Aubin, J.P.: Viability Theory. Birkhäuser, Basel (1991)

Arrow, K.J., Hurwicz, L., Uzawa, H.: Constraint qualifications in maximization problems. Nav. Res. Logist. Q. 8, 175-191 (1961)

Asheim, G.B.: Hartwick's rule. In: Shogren, J. (ed.) Encyclopedia of Energy, Natural Resource and Environmental Economics, vol. 2, pp. 314-320. Elsevier, Amsterdam (2013)

Asheim, G.B., Buchholz, W., Withagen, C.: Hartwick's rule: myths and facts. Environ. Resour. Econ. 25, 129-150 (2003)

Buchholz, W., Dasgupta, S., Mitra, T.: Intertemporal equity and Hartwick's rule in an exhaustible resource model. Scand. J. Econ. 107, 547-561 (2005)

Burmeister, E., Hammond, P.: Maximin paths of heterogeneous capital accumulation and the instability of paradoxical steady states. Econometrica 45, 853-870 (1977)

Cass, D., Mitra, T.: Indefinitely sustained consumption despite exhaustible natural resources. Econ. Theory 1, 119-146 (1983)

Dasgupta, P.S., Heal, G.M.: The optimal depletion of exhaustible resources. Rev. Econ. Stud. 41(Symposium), 3-28 (1974)

Dasgupta, S., Mitra, T.: Intergenerational equity and efficient allocation of exhaustible resources. Int. Econ. Rev. 24, 133-153 (1983)

Dixit, A., Hammond, P., Hoel, M.: On Hartwick's rule for regular maximin paths of capital accumulation and resource depletion. Rev. Econ. Stud. 47, 551-556 (1980)

Doyen, L., Gajardo, P.: Sustainability standards, multicriteria maximin, and viability. Nat. Resour. Model. (2019). https://doi.org/10.1111/nrm.12250

Doyen, L., Martinet, V.: Maximin, viability and sustainability. J. Econ. Dyn. Control 36, 1414-1430 (2012)

Fleurbaey, M.: On sustainability and social welfare. J. Environ. Econ. Manag. 71, 34-53 (2015)

Hartwick, J.M.: Intergenerational equity and investing rents from exhaustible resources. Am. Econ. Rev. 66, 972-974 (1977)

Malinvaud, E.: Capital accumulation and efficient allocation of resources. Econometrica 21, 233-268 (1953)

Martinet, V., Doyen, L.: Sustainability of an economy with an exhaustible resource: a viable control approach. Resour. Energy Econ. 29, 17-39 (2007)

Mitra, T.: Efficient growth with exhaustible resources in a neoclassical model. J. Econ. Theory 17, 114$129(1978)$

Mitra, T.: Intertemporal equity and efficient allocation of resources. J. Econ. Theory 107, 356-376 (2002)

Mitra, T., Asheim, G.B., Buchholz, W., Withagen, C.: Characterizing the sustainability problem in an exhaustible resource model. J. Econ. Theory 148, 2164-2182 (2013)

Nikaido, H.: Convex Structures and Economic Theory. Academic Press, New York (1968)

Pezzey, J.C.V.: Sustainability constraints versus "optimality" versus intertemporal concern, and axioms versus data. Land Econ. 73, 448-466 (1997)

Rudin, W.: Principles of Mathematical Analysis, 3rd edn. McGraw-Hill, New York (1976)

Solow, R.M.: Intergenerational equity and exhaustible resources. Rev. Econ. Stud. 41(Symposium), 29-45 (1974)

Withagen, C., Asheim, G.B.: Characterizing sustainability: the converse of Hartwick's rule. J. Econ. Dyn. Control 23, 159-165 (1998)

Publisher's Note Springer Nature remains neutral with regard to jurisdictional claims in published maps and institutional affiliations. 